\title{
The midline mandibular lingual canal: importance in implant
}

\section{surgery}

Anna C. Oettlé, Dr MBBCh, MSc (Anat) ${ }^{1} /$ Jeanine Fourie, Dr MChD²/René Human-Baron, Mrs MSc (Anat) ${ }^{3} /$ André W. van Zyl, Ass Prof MChD ${ }^{4}$

1. Senior lecturer, Department of Anatomy, School of Medicine, University of Pretoria, Republic of South Africa

2. Lecturer, Department of Periodontics and Oral Medicine, School of Dentistry, University of Pretoria, Republic of South Africa

3. Junior lecturer, Department of Anatomy, School of Medicine, University of Pretoria, Republic of South Africa

4. Ass Professor and head of the Department of Periodontics and Oral Medicine, School of Dentistry, University of Pretoria, Republic of South Africa

Corresponding author:

Ass Prof. A.W. van Zyl,

Department of Periodontics and Oral Medicine

PO Box 1266

Pretoria

0001

Republic of South Africa

Telephone: +27 123192312

Facsimile: +27 123263375

E mail: andre.vanzyl@up.ac.za 
Running title: Implants near the midline mandibular lingual canal

\section{Abstract}

Purpose: To determine the position and occurrence of the midline mandibular canal (MLC) in the various age, sex, population and dentition groups. The average distances from the MLC to a planned mandibular midline implant and the inferior mandibular border were measured. Materials and methods: Cone beam computed tomography (CBCT) was used to scan 122 mandibles (31 black males; 28 black females; 32 white males and 31 white females). Midsagittal sections in the reconstructed images of edentulous mandibles or sagittal sections through the socket of the 41 tooth (FDI nomenclature) in dentate mandibles were made. A measurement of $6 \mathrm{~mm}$ across buccolingually (BL) was delineated with the caliper tool indicating the minimum dimensions for placement of an implant. In dentate cases where the BL distance was in excess of $6 \mathrm{~mm}$, the caliper was placed across the deepest part of the socket as a marker to determine the bone dimension available below the socket for implant placement. From these markers a vertical line was dropped to the MLC to measure the available bone. Results: The MLC was a consistent finding within the anterior mandible. A statistical significant difference in bone availability amongst the sexes and with dentition pattern was found indicating that edentulous female patients were particularly at risk of injury to the vessels of the midline lingual canal during implants in that area. Conclusion: Immediate implants in the position of lower central incisors are regarded as a safe procedure as is the placement of interforaminal implants in the anterior mandible. Clinicians should however take note of the position of the midline mandibular lingual canal and approach this area with caution, especially if the alveolar ridge is to be reduced before implant placement.

Key words: Near-fatal bleeding; lingual foramen; edentulous; sublingual artery; submental artery 


\section{Introduction}

The midline lingual canal (MLC) of the mandible contains a blood vessel that may hemorrhage if perforated and should be considered when dental implants are planned. ${ }^{1}$ The consequences of the perforation of this blood vessel may be serious as it may lead to a near fatal bleeding incident due to the obstruction of the airway (Fig 1$)^{2-4}$

The proximity of any planned implant site to the MLC is therefore pivotal. This study was done to determine whether the average distance from the midline lingual canal to the $31 / 41$ (FDI nomenclature) or midline planned implant site, was clinically significant. This distance is especially important when an immediate implant is planned to replace the 31 or 41 tooth or when the anterior mandibular alveolar ridge is reduced to create a platform for inter-foraminal implants. Immediate implants are often placed deeper than the pre-existing socket to obtain primary stability, which could damage the MLC and its blood vessel. Reduction of the anterior mandible to create a platform for implant placement has become an accepted procedure which may also lead to damage to the MLC position. Previous studies focused on the distance of the inferior border of the mandible to the lingual foramen or canal. ${ }^{1,5-15}$

The midline lingual foramen leading into the MLC is a constant feature of the anterior mandible as $81-100 \%$ of patients have at least one such foramen. ${ }^{5-11,13,14,16-22}$ Some authors refer to this foramen as the midline lingual foramen; to distinguish it from the more laterally situated lingual foramen. ${ }^{6,19}$ We prefer the term midline lingual canal as it describes the anatomic structure containing the artery and not just the entry point. It is more likely that a clinician will damage the artery just inside the mandibular body, rather than at the site of the foramen. 
The foramen is found superior to or at the level of the mental spines or genial tubercles in the midline of the mandible..$^{5,7,9,13,14,18}$ There may be two or more foramina present in the midline and their locations and dimensions are variable. ${ }^{11}$

The contents of the MLC have not been clarified and are under debate. ${ }^{18}$ Some researchers suggest that a neurovascular bundle enters through the foramen ${ }^{11,23}$ while others have found that the canal contains an artery only. ${ }^{8,24}$

Lustig et al, (2003) found the average diameter of the artery to be $1.41 \mathrm{~mm} \pm 0.34 \mathrm{~mm}$ with an average blood flow of $2.92 \pm 3.19 \mathrm{ml} / \mathrm{min}$, while Jaju and Jaju reported a mean diameter of $0.31 \mathrm{~mm}$ $\pm 0.7 \mathrm{~mm}$ with the largest diameter being $1.6 \mathrm{~mm} \cdot{ }^{21,24} \mathrm{It}$ is therefore clear that the artery entering the lingual foramen is of sufficient size to cause hemorrhage intra-osseous or in the floor of the mouth when the lingual cortex is perforated. ${ }^{2,4,19,24-26}$ Should the artery be perforated close to the lingual border of the mandible, it is conceivable that the bleeding will spread into the floor of the mouth, with the risk of obstructing the airway as has previously been described. ${ }^{2,4,9}$

Successful implant surgery is dependent on sufficient bone quantity and quality. ${ }^{27-29}$ Convention dictates that a border of at least $1 \mathrm{~mm}$ on both the lingual and buccal sides should surround the implant osteotomy site. Standard sized implants are $+/-4 \mathrm{~mm}$ in diameter, implying that a minimum bone dimension of $6 \mathrm{~mm}$ is required for successful implant placement. ${ }^{29-31}$

Implant placement in thin ridges is often abandoned as the implant strength and surface area for load distribution is greatly reduced. ${ }^{32}$ On the other hand, reducing the thin alveolar ridge to obtain a width of $6 \mathrm{~mm}$ in such cases decreases the vertical dimension of the implant site. ${ }^{28}$ Vertical reduction may also be required to establish sufficient vertical restorative space, especially in cases 
where the anterior mandibular segment has over-erupted in response to loss of maxillary teeth. The reduction of the alveolar bone in such a manner may pose a risk if a midline implant is considered, as it will encroach on the MLC position.

Trauma to the artery within the MLC may lead to serious hemorrhage if the size of the artery exceeds $1 \mathrm{~mm} .^{4,22}$ The main hazard of such hemorrhage is airway obstruction caused by hematoma formation in the floor of the mouth which results in swelling that pushes the tongue against the palate. ${ }^{9}$ This may lead to near fatal bleeding incidents. ${ }^{3,4,25,33-49}$ The risk of hemorrhage is further increased in edentulous patients having atrophic mandibles with resorption of the alveolar ridge. ${ }^{7}$

It is difficult to visualize the lingual foramen with conventional radiographs. ${ }^{12}$ Natekar et al (2011) observed the lingual foramen in only $28 \%$ of cases. ${ }^{23}$ Computer-assisted imaging systems such as cone beam computed tomography $(\mathrm{CBCT})$ is recommended as almost all lingual foramina can be visualized, the correct implant size can be calculated and surgical complications reduced. ${ }^{1,10,12,22}$ It further has the benefit of a lower radiation dose than medical multi-slice computed tomography. ${ }^{10}$

In the literature search no studies could be found that compare different population groups with regards to the position and occurrence of the lingual canal and only a few that compared sexes and populations. $^{20,21,50}$ 
The purpose of the study was to determine the position and occurrence of the midline mandibular canal in the various age, sex, population and dentition groups. The average distance from the midline lingual canal (MLC) to a planned implant site in the midline of the mandible was measured to determine the feasibility of such a midline implant.

\section{Materials and methods}

\section{Materials}

The study sample consisted of 122 dried mandibles belonging to two South African population groups and both sexes: 31 black males; 28 black females; 32 white males and 31 white females. Representatives of three dentition pattern subgroups are included in each sex- and population group. Dentition patterns were introduced to distinguish between the degree of tooth loss which has functional implications for mastication and the forces exerted on the mandible and therefore potentially for the distances measured. The three dentition pattern subgroups are the following: edentulous (dentition pattern 0); those with fewer than two occlusions of molars or premolars and fewer than one occlusion of canines or incisors on either side (dentition pattern 1 ) and those with at least two occlusions of molars and premolars or at least one occlusion of canines and incisors on either side (dentition pattern 2).

\section{Methods}

Dried mandibles were scanned at Necsa (South African Nuclear Energy Corporation Ltd) which hosts the South African Neutron Radiography (SANRAD) and tomography facility capable of producing $\mathrm{CBCT}^{51}$ The reconstruction of $370 \mathrm{X}$-rays per section was performed through Octopus ${ }^{\circledR}$ software, a commercial tomography reconstruction package for $\mathrm{CBCT}$, which first converts the raw projections into tiff image stacks of two-dimensional cross- sections through the sample. 
The slices were stacked to produce a virtual voxel volume representing the sample in threedimensions in a software package. The VG Studio MAX-2.1 software from Volume-Graphics was used for the three-dimensional rendering, segmentation and visualization of the reconstructed volume data (Volume Graphics, 2010). The distances were measured by integrating the information provided by the three-dimensional image together with the axial, sagittal and frontal views.

If no teeth were present, a midsagittal section of the 3D-reconstructed mandible was made to enable measurements. When teeth were present the sagittal section was made through the deeper part of the socket of tooth 41 and inspected for the presence of midline lingual canal/s. If a canal was not immediately obvious the images were scrolled sequentially until such a canal could be found near the midline.

If the mandible was wide enough to allow a measurement of $6 \mathrm{~mm}$ bucco-lingually (BL) it was delineated with the caliper tool in VG studio max (Figs. 3, 4a and b). In six cases (four white females, one black male and one white male) the section was not wide enough to allow a measurement of 6 $\mathrm{mm} \mathrm{BL}$ and the superior distance was indicated as zero, as no distance was considered available for placing a $4 \mathrm{~mm}$ implant safely. In dentate cases where the BL distance was in excess of $6 \mathrm{~mm}$, the caliper was placed across the deepest part of the socket to simulate reduction of the alveolar bone in order to obtain primary stability for immediate implant placement. From this marker a vertical line was dropped into the medullary bone to measure the closest distance to the midline lingual canal: the superior distance (Fig 5).

A second measurement was taken from the superior midline lingual canal to the inferior border of the mandible: the inferior distance (Figs. 3, 4a and b). Very small canals even if superior to a main canal were not taken into account as were canals that pierced the cortex but did not reach the medulla of the bone. 
The mean and standard deviations were calculated for each of the four sex, population and dentition groups for the superior and inferior distance. Statistical comparisons between groups were done using analysis of covariance (ANCOVA) correcting for age if it was found to be a significant covariate.

Ethics considerations

Ethics approval was obtained from the Ethics Committee of the Faculty of Health Sciences of the University of Pretoria (Protocol no: 120/2010).

\section{Results}

\section{Inferior distance}

Basic descriptive analysis for the inferior distance was performed and is presented in Tables 1 to 3 .

ANCOVA showed no statistical difference according to sex $(p=0.13)$, age $(p=0.27)$ population group $(p=0.61)$ or dentition pattern $(p=0.79)$ for inferior distances.

\section{Superior distance}

Basic descriptive analysis for the superior distance was performed and is presented in Tables 4 to 6 .

ANCOVA for the superior distance exhibited a significant difference amongst the sexes $(p=0.0044)$ and dentition patterns $(p=0.0006)$. As evident from Tables 4 to 6 , the superior distance was significantly shorter in females and edentulous individuals. The difference between populations was not significant $(p=0.5337)$. Age was not a significant covariate and none of the interactions between the main factors (sex; dentition pattern or population) were significant. 


\section{Course of the MLC}

It was found that the midline lingual canals situated more superior, progressed in an antero-inferior direction while those canals located inferior showed an antero-superior direction. In some instances the canals anastomosed to form one continuous canal connecting the superior lingual foramen with the inferior lingual foramen (Fig 6). In other cases the canals of the lingual foramen seemed to bifurcate (Fig 7).

\section{Discussion}

The direction of the canals described in this study is similar to that described by other researchers. ${ }^{1,5,6,20}$ It has been reported that the artery of the MLC anastomoses with the incisive artery. ${ }^{5,13,16}$ Others describe the course of the MLC as extending from the lingual side towards the buccal or vestibular side, thereby connecting the lingual and labial plates. ${ }^{16,20}$ No reports however have described an anastomosis between the canals of the more superiorly located lingual foramina and the more inferiorly located canals as seen in this study. One can postulate that the lingual canals follow this circular pathway to run towards a capillary bed contained within the cancellous bone of the mandible providing nutrients to the mandible. Such an area might explain excessive bleeding during implant drilling or harvesting of bone blocks from the chin.

The bifurcation of the lingual canals as seen in this study may pose an additional risk for injury as the bifurcation may be in the path of the implant preparation site.

In some cases where hemorrhage has been reported, a drilling depth of $15 \mathrm{~mm}$ was used. ${ }^{7}$ This depth would have posed a risk to the individuals in this study (Tables 4-6). The risk of hemorrhage is further increased in edentulous patients with atrophic mandibles ${ }^{7}$ or where the alveolar ridge is reduced for immediate implant placement and loading. Reduction of the mandible is often done to 
obtain primary stability for the dental implant which is not always possible within a tooth socket and also to flatten the anterior alveolar ridge in the mandible for prosthetic purposes. A maximum implant length of $14 \mathrm{~mm}$ has been proposed in the anterior mandible to lessen the chances of complications. $^{36}$

No statistical variation was found for the inferior distance with a mean distance ranging from 10.83 to 12.874 for all groups.

The statistical variation noted in the superior distance between sexes and dentition groups necessitates the need to consider these factors when planning implants in the midline of the mandible. Some clinical protocols require 5 implants inter-foraminal, where limited space between the mental foramina might force the clinician into a midline position. Other clinical protocols require the reduction of the anterior mandible in order to do immediate placement and loading of implants. Such a reduction might encroach on the midline lingual canal amongst others, and may lead to a near fatal bleeding incident if the MLC is perforated close to the lingual foramen. The replacement of teeth 41 and 31 with dental implants should also be approached with caution, for both immediate and late placement protocols. The proximity of the root apex of these teeth to the MLC might pose a risk for vascular injury.

If $8 \mathrm{~mm}$ is considered the minimum implant length required below a BL width of $6 \mathrm{~mm}$ the mean value of edentulous females and some with variable number of teeth will not qualify for implantation in the midline without endangering the vessels in the midline lingual canals. Furthermore, the suggested safety margin of $2 \mathrm{~mm}$ between a dental implant and neurovascular structures would not be maintained. In males, some edentulous individuals will also not qualify although the mean value is adequate in this group. Dentate males seem as a group to have adequate height of alveolar bone needed for dental implants in the midline without endangering the vessels of the midline lingual canals. 


\section{Conclusion}

The MLC is a consistent finding within the anterior mandible. It is of surgical significance as it contains a blood vessel that may lead to hemorrhage and life-threatening conditions when perforated. Clinicians should take note of its presence and approach the area with caution. Panoramic radiographs are often the only diagnostic aid used in the anterior mandible and does not show the lingual canal. We therefore recommend the use of computed tomography in pre-operative assessment of implants in the midline mandibular area as the standard of care.

\section{Acknowledgements}

This research was partly funded by the research committee of the Faculty of Health Sciences, University of Pretoria. The authors wish to acknowledge Mr FC de Beer and his team from Necsa (Nuclear Energy Corporation of South Africa), SANRAD (South African Neutron Radiography facility), Pelindaba, Republic of South Africa for the scanning of all specimens and the 3D-reconstructions thereof. Our appreciation also goes to Prof PJ Becker from the Biostatistics Unit, Medical Research Council, Pretoria, Republic of South Africa for the statistical analyses. 
Figures:

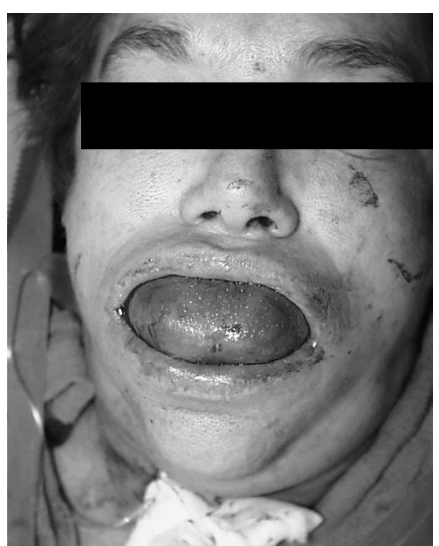

Figure 1: Near fatal bleeding incident after perforation of a blood vessel in the anterior floor of the mouth during routine implant placement in the anterior mandible (Photo courtesy of Joe Niamtu III)

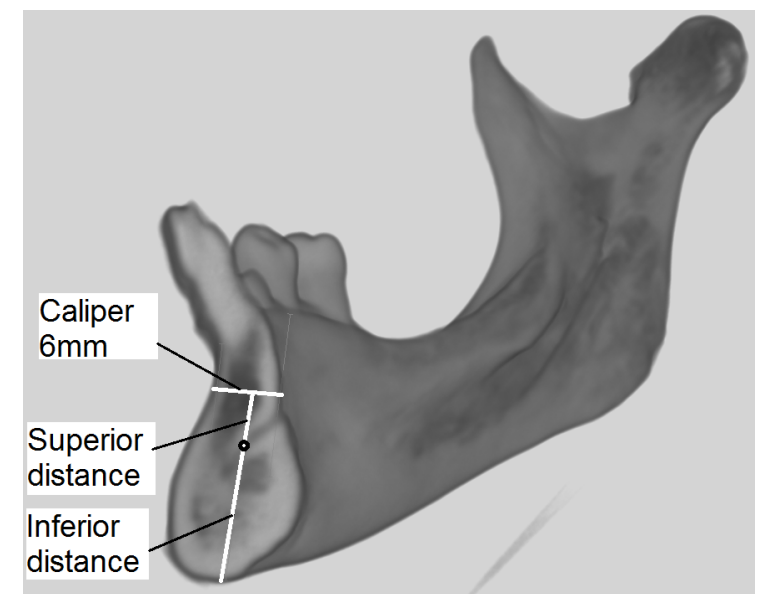

Figure 2: Midsagittal section of a reconstructed Cone Beam Computed Tomography (CBCT) image of the mandible demonstrating the midline lingual canal 


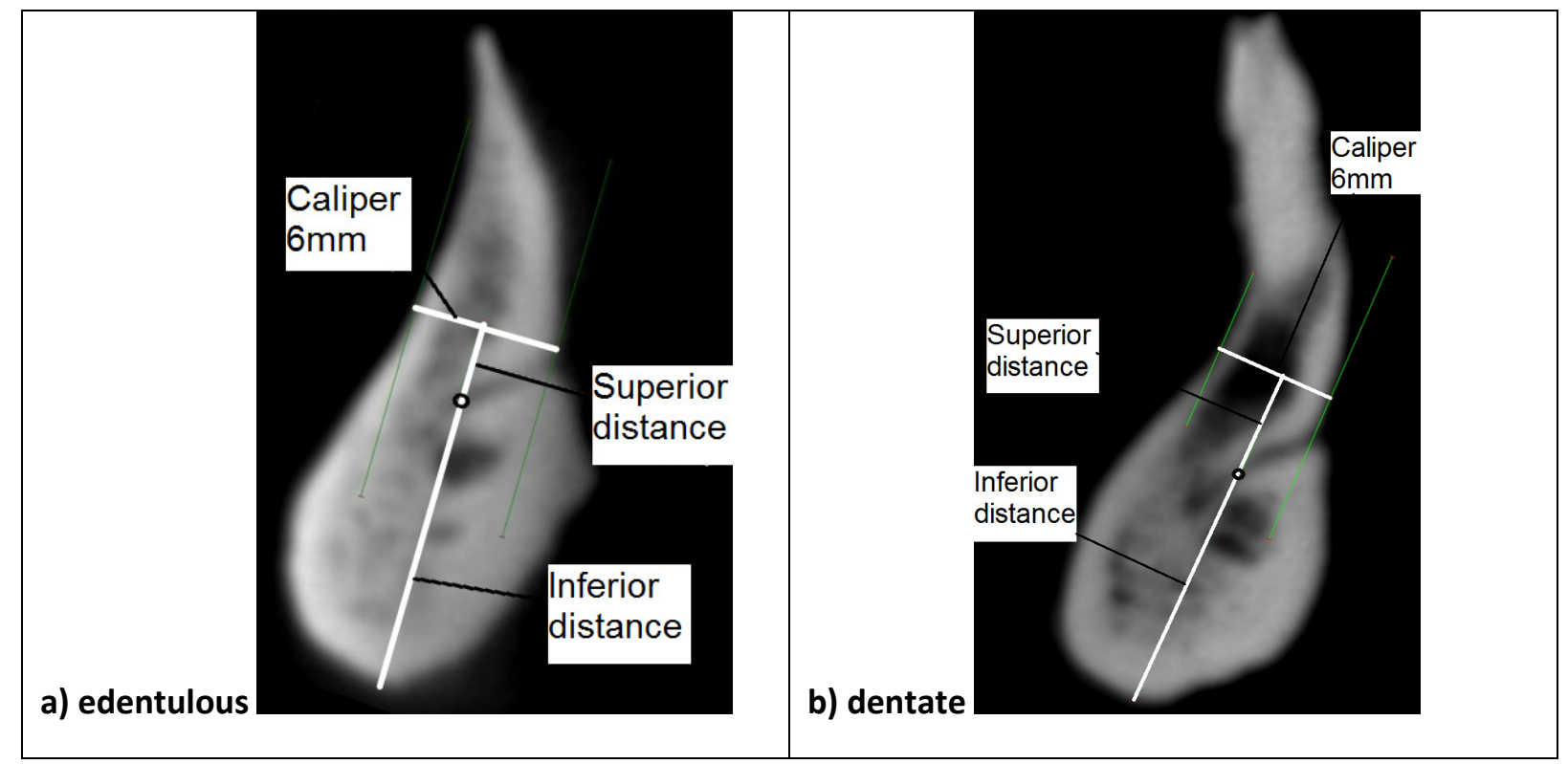

Figure 3: Midsagittal section of a reconstructed image showing the superior and inferior measurements

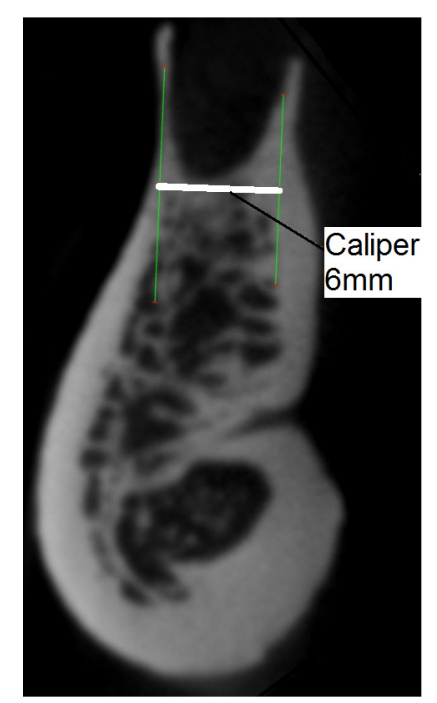

Figure 4: Calliper position across the deepest part of the extraction cavity coinciding with root apex



Figure 5: Continuity between superior and inferior lingual foramen 


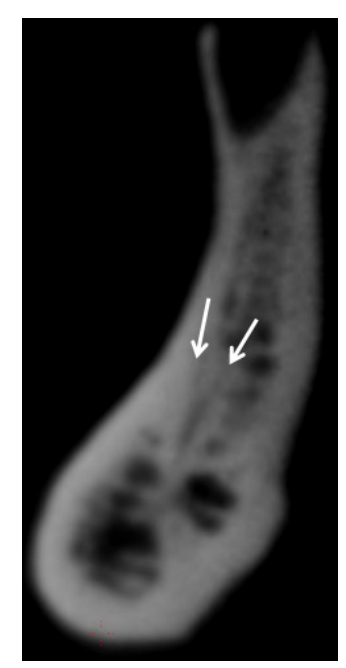

Figure 6: Bifurcation of lingual canal 
Tables:

Table 1: The inferior distance amongst the sexes and dentition patterns measured in $\mathrm{mm}$

\begin{tabular}{|l|l|l|l|}
\hline Sex $\rightarrow$ & Male & Total \\
\hline 0 & $\mathrm{~N}=20$ & $\mathrm{~N}=20$ & $\mathrm{~N}=40$ \\
\hline edentulous & $10.83+/-3.17$ & $12.87+/-2.68$ & $11.85+/-3.08$ \\
\hline 1 & $\mathrm{~N}=25$ & $\mathrm{~N}=14$ & $\mathrm{~N}=39$ \\
\hline $\begin{array}{l}\text { fewer than two occlusions of } \\
\text { molars or premolars and fewer } \\
\text { than one occlusion of canines } \\
\text { or incisors on either side }\end{array}$ & $11.05+/-2.15$ & $11.71+/-2.95$ & $11.29+/-2.45$ \\
\hline $\begin{array}{l}\text { Total } \\
2\end{array}$ & $\mathrm{~N}=14$ & $\mathrm{~N}=27$ & $\mathrm{~N}=61$ \\
\hline $\begin{array}{l}\text { least one occlusion of canines } \\
\text { and incisors on either side } \\
\text { molars and premolars or at }\end{array}$ & $12.27+/-2.52$ & $11.53+/-1.83$ & $11.79+/-2.09$ \\
\hline least two occlusions of & $\mathrm{N}=59$ & $\mathrm{~N}=41$ \\
\hline
\end{tabular}


Table 2: The inferior distance amongst the sexes and population groups measured in $\mathbf{m m}$

\begin{tabular}{|l|l|l|l|}
\hline Sex $\rightarrow$ & & Male & Total \\
\hline Population groups $\downarrow$ & Female & $\mathrm{N}=26$ & $\mathrm{~N}=56$ \\
\hline Black & $\mathrm{N}=30$ & $11.87+/-2.6$ & $11.62+/-2.58$ \\
\hline White & $11.40+/-2.58$ & $\mathrm{~N}=35$ & $\mathrm{~N}=64$ \\
\hline & $\mathrm{N}=29$ & $12.12+/-2.36$ & $11.67+/-2.57$ \\
\hline & $11.13+/-2.74$ & $\mathrm{~N}=61$ & $\mathrm{~N}=120$ \\
\hline & $11.27+/-2.64$ & $12.01+/-2.45$ & $11.65+/-2.56$ \\
\hline
\end{tabular}


Table 3: The inferior distance amongst the dentition patterns and population groups measured in $\mathbf{m m}$

\begin{tabular}{|c|c|c|c|}
\hline $\begin{array}{l}\text { Population groups } \rightarrow \\
\text { Dentition pattern } \downarrow\end{array}$ & Black & White & Total \\
\hline $\begin{array}{l}0 \\
\text { edentulous }\end{array}$ & $\begin{array}{l}N=13 \\
11.45(2.64)\end{array}$ & $\begin{array}{l}N=27 \\
12.04\end{array}$ & $\begin{array}{l}N=40 \\
11.85(3.08)\end{array}$ \\
\hline $\begin{array}{l}1 \\
\text { fewer than two occlusions of } \\
\text { molars or premolars and fewer } \\
\text { than one occlusion of canines } \\
\text { or incisors on either side }\end{array}$ & $N=19$ & $N=20$ & $N=39$ \\
\hline $\begin{array}{l}2 \\
\text { at least two occlusions of } \\
\text { molars and premolars or at } \\
\text { least one occlusion of canines } \\
\text { and incisors on either side }\end{array}$ & $N=24$ & $11.85(1.52)$ & $N=41$ \\
\hline Total & $\begin{array}{l}N=56 \\
11.62 \quad(2.58)\end{array}$ & $\begin{array}{l}\mathrm{N}=64 \\
11.67 \quad(2.57)\end{array}$ & $\begin{array}{l}N=120 \\
11.65(2.56)\end{array}$ \\
\hline
\end{tabular}


Table 4: The superior distance amongst the sexes and dentition patterns measured in $\mathrm{mm}$

\begin{tabular}{|c|c|c|c|}
\hline $\begin{array}{l}\text { Sex } \rightarrow \\
\text { Dentition pattern } \downarrow\end{array}$ & Female & Male & Total \\
\hline $\begin{array}{l}0 \\
\text { edentulous }\end{array}$ & $\begin{array}{l}N=20 \\
6.02+/-4.88\end{array}$ & $\begin{array}{l}N=20 \\
8.18+/-5.06\end{array}$ & $\begin{array}{l}N=40 \\
7.10+/-5.03\end{array}$ \\
\hline $\begin{array}{l}1 \\
\text { fewer than two occlusions of } \\
\text { molars or premolars and fewer } \\
\text { than one occlusion of canines } \\
\text { or incisors on either side }\end{array}$ & $\begin{array}{l}N=25 \\
9.39+/-3.45\end{array}$ & $N=14$ & $N=39$ \\
\hline $\begin{array}{l}2 \\
\text { at least two occlusions of } \\
\text { molars and premolars or at } \\
\text { least one occlusion of canines } \\
\text { and incisors on either side }\end{array}$ & $N=14$ & $N=27$ & $N=41$ \\
\hline Total & $\begin{array}{l}N=59 \\
8.21+/-4.13\end{array}$ & $\begin{array}{l}N=61 \\
10.65+/-4.98\end{array}$ & $\begin{array}{l}N=120 \\
9.45+/-4.72\end{array}$ \\
\hline
\end{tabular}


Table 5: The superior distance amongst the sexes and population groups measured in $\mathrm{mm}$

\begin{tabular}{|l|l|l|l|}
\hline Sex $\rightarrow$ & & Male & Total \\
\hline Black & $\mathrm{N}=30$ & $\mathrm{~N}=26$ & $\mathrm{~N}=56$ \\
& $9.09+/-3.78$ & $10.99+/-4.65$ & $9.97+/-4.27$ \\
\hline White & $\mathrm{N}=29$ & $\mathrm{~N}=35$ & $\mathrm{~N}=64$ \\
\hline Total & $7.30+/-4.35$ & $10.4+/-5.27$ & $8.99+/-5.08$ \\
& $\mathrm{~N}=59$ & $\mathrm{~N}=61$ & $\mathrm{~N}=120$ \\
\hline & $8.20+/-4.13$ & $10.65+/-4.98$ & $9.45+/-4.72$ \\
\hline
\end{tabular}


Table 6: The superior distance amongst the dentition patterns and population groups measured in $\mathbf{m m}$

\begin{tabular}{|c|c|c|c|}
\hline $\begin{array}{l}\text { Populations } \rightarrow \\
\text { Dentition pattern } \downarrow\end{array}$ & Black & White & Total \\
\hline $\begin{array}{l}0 \\
\text { edentulous }\end{array}$ & $\begin{array}{l}N=13 \\
8.45+/-4.37\end{array}$ & $\begin{array}{l}N=27 \\
6.46+/-5.27\end{array}$ & $\begin{array}{l}N=40 \\
7.10+/-5.03\end{array}$ \\
\hline $\begin{array}{l}1 \\
\text { fewer than two occlusions of } \\
\text { molars or premolars and fewer } \\
\text { than one occlusion of canines } \\
\text { or incisors on either side }\end{array}$ & $\begin{array}{l}N=19 \\
9.17+/-4.18\end{array}$ & $10.89+/-4.22$ & $N=39$ \\
\hline $\begin{array}{l}2 \\
\text { at least two occlusions of } \\
\text { molars and premolars or at } \\
\text { least one occlusion of canines } \\
\text { and incisors on either side }\end{array}$ & $N=24$ & $N=17$ & $N=41$ \\
\hline Total & $\begin{array}{l}N=56 \\
9.97+/-4.27\end{array}$ & $\begin{array}{l}N=64 \\
8.99+/-5.08\end{array}$ & $\begin{array}{l}N=120 \\
9.45+/-4.72\end{array}$ \\
\hline
\end{tabular}


References:

1. Kawai T, Asaumi R, Sato I, Yoshida S, Yosue T. Classification of the lingual foramina and their bony canals in the median region of the mandible: cone beam computed tomography observations of dry Japanese mandibles. Oral Radiology 2007; 23: 42-8.

2. Loukas M, Kinsella CR, Jr., Kapos T, Tubbs RS, Ramachandra S. Anatomical variation in arterial supply of the mandible with special regard to implant placement. Int J Oral Maxillofac Surg 2008; 37: 367-71.

3. Kalpidis CD, Setayesh RM. Hemorrhaging associated with endosseous implant placement in the anterior mandible: a review of the literature. J Periodontol 2004; 75: 631-45.

4. Flanagan D. Important arterial supply of the mandible, control of an arterial hemorrhage, and report of a hemorrhagic incident. J Oral Implantol 2003; 29: 165-73.

5. von Arx T, Matter D, Buser D, Bornstein MM. Evaluation of location and dimensions of lingual foramina using limited cone-beam computed tomography. J Oral Maxillofac Surg 2011; 69: 2777-85.

6. Tagaya A, Matsuda Y, Nakajima K, Seki K, Okano T. Assessment of the blood supply to the lingual surface of the mandible for reduction of bleeding during implant surgery. Clin Oral Implants Res 2009; 20: 351-5.

7. Scaravilli MS, Mariniello M, Sammartino G. Mandibular lingual vascular canals (MLVC): evaluation on dental CTs of a case series. Eur J Radiol 2010; 76: 173-6.

8. Rosano G, Taschieri S, Gaudy JF, Testori T, Del Fabbro M. Anatomic assessment of the anterior mandible and relative hemorrhage risk in implant dentistry: a cadaveric study. Clin Oral Implants Res 2009; 20: 791-5.

9. Mraiwa N, Jacobs R, van Steenberghe D, Quirynen M. Clinical assessment and surgical implications of anatomic challenges in the anterior mandible. Clin Implant Dent Relat Res 2003; 5: 219-25.

10. Makris N, Stamatakis H, Syriopoulos K, Tsiklakis K, van der Stelt PF. Evaluation of the visibility and the course of the mandibular incisive canal and the lingual foramen using cone-beam computed tomography. Clin Oral Implants Res 2010; 21: 766-71.

11. Liang $X$, Jacobs $R$, Lambrichts I, Vandewalle $G$. Lingual foramina on the mandibular midline revisited: a macroanatomical study. Clin Anat 2007; 20: 246-51.

12. Kawai T, Sato I, Yosue T, Takamori H, Sunohara M. Anastomosis between the inferior alveolar artery branches and submental artery in human mandible. Surg Radiol Anat 2006; 28: 30810.

13. Katakami K, Mishima A, Kuribayashi A, Shimoda S, Hamada Y, Kobayashi K. Anatomical characteristics of the mandibular lingual foramina observed on limited cone-beam CT images. Clin Oral Implants Res 2009; 20: 386-90.

14. Gahleitner A, Hofschneider U, Tepper G, et al. Lingual vascular canals of the mandible: evaluation with dental CT. Radiology 2001; 220: 186-9. 
15. Cova M, Ukmar M, Bole T, Morra A, Lubin E, Pozzi Mucelli R. Evaluation of lingual vascular canals of the mandible with Computed Tomography. Radiol Med 2003; 106: 391-8.

16. Trikeriotis D, Paravalou E, Diamantopoulos P, Nikolaou D. Anterior mandible canal communications: a potential portal of entry for tumour spread. Dentomaxillofac Radiol 2008; 37 : 125-9.

17. Singh V, Anand MK, Dinesh K. Variations in the pattern of mental spines and spinous mental foramina in dry adult human mandibles. Surg Radiol Anat 2000; 22: 169-73.

18. Mraiwa N, Jacobs R, Moerman P, Lambrichts I, van Steenberghe D, Quirynen M. Presence and course of the incisive canal in the human mandibular interforaminal region: two-dimensional imaging versus anatomical observations. Surg Radiol Anat 2003; 25: 416-23.

19. McDonnell D, Reza Nouri M, Todd ME. The mandibular lingual foramen: a consistent arterial foramen in the middle of the mandible. J Anat 1994; 184 ( Pt 2): 363-9.

20. Liang $X$, Jacobs R, Lambrichts I. An assessment on spiral CT scan of the superior and inferior genial spinal foramina and canals. Surg Radiol Anat 2006; 28: 98-104.

21. Jaju P, Jaju S. Lingual vascular canal assessment by dental computed tomography: a retrospective study. Indian J Dent Res 2011; 22: 232-6.

22. Babiuc I TI, Pauna M. Cone beam computed tomography observations of the lingual foramina and their bony canals in the median region of the mandible. Rom J Morphol Embryol 2011; 52: 827-9.

23. Natekar PE DSF, Natekar P. Variations in position of lingual foramen of the mandible in reconstructive surgery. Indian Journal of Otology 2011; 17: 12-3.

24. Lustig JP, London D, Dor BL, Yanko R. Ultrasound identification and quantitative measurement of blood supply to the anterior part of the mandible. Oral Surg Oral Med Oral Pathol Oral Radiol Endod 2003; 96: 625-9.

25. Woo BM, Al-Bustani S, Ueeck BA. Floor of mouth haemorrhage and life-threatening airway obstruction during immediate implant placement in the anterior mandible. Int J Oral Maxillofac Surg 2006; 35: 961-4.

26. Nagar M BR, Prakash R. Accessory lingual foramen in adult Indian mandibles. J Anat Soc India 2001; 50: 13-4.

27. Widmark G, Andersson B, Ivanoff CJ. Mandibular bone graft in the anterior maxilla for singletooth implants. Presentation of surgical method. Int J Oral Maxillofac Surg 1997; 26: 106-9.

28. van den Bergh JP, ten Bruggenkate $\mathrm{CM}$, Tuinzing DB. Preimplant surgery of the bony tissues. J Prosthet Dent 1998; 80: 175-83.

29. Van Assche N, van Steenberghe D, Guerrero ME, et al. Accuracy of implant placement based on pre-surgical planning of three-dimensional cone-beam images: a pilot study. J Clin Periodontol 2007; 34: 816-21.

30. Tolstunov L. Implant zones of the jaws: implant location and related success rate. J Oral Implantol 2007; 33: 211-20.

31. Dene L, Condos S. Ridge expansion and immediate implant placement in the esthetic zone. $\mathrm{N}$ Y State Dent J 2010; 76: 28-31.

32. Palmer P, Palmer R. Dental implants. 8. Implant surgery to overcome anatomical difficulties. Br Dent J 1999; 187: 532-40.

33. Krenkel C, Holzner K. [Lingual bone perforation as causal factor in a threatening hemorrhage of the mouth floor due to a single tooth implant in the canine region]. Quintessenz 1986; 37: 1003-8.

34. Kalpidis CD, Konstantinidis AB. Critical hemorrhage in the floor of the mouth during implant placement in the first mandibular premolar position: a case report. Implant Dent 2005; 14: 117-24.

35. Isaacson TJ. Sublingual hematoma formation during immediate placement of mandibular endosseous implants. J Am Dent Assoc 2004; 135: 168-72. 
36. Givol N, Chaushu G, Halamish-Shani T, Taicher S. Emergency tracheostomy following lifethreatening hemorrhage in the floor of the mouth during immediate implant placement in the mandibular canine region. J Periodontol 2000; 71: 1893-5.

37. Girdler NM. Fatal sequel to dental implant surgery. J Oral Rehabil 1994; 21: 721-2.

38. Frenken JW, Zijderveld SA, van den Bergh JP, Huisman FW, Cune MS. [Haematoma of the floor of the mouth following implant surgery]. Ned Tijdschr Tandheelkd 2010; 117: 17-21.

39. Pigadas N, Simoes P, Tuffin JR. Massive sublingual haematoma following osseo-integrated implant placement in the anterior mandible. Br Dent J 2009; 206: 67-8.

40. Panula K, Oikarinen K. Severe hemorrhage after implant surgery. Oral Surg Oral Med Oral Pathol Oral Radiol Endod 1999; 87: 2.

41. Niamtu J, 3rd. Near-fatal airway obstruction after routine implant placement. Oral Surg Oral Med Oral Pathol Oral Radiol Endod 2001; 92: 597-600.

42. Mordenfeld A, Andersson L, Bergstrom B. Hemorrhage in the floor of the mouth during implant placement in the edentulous mandible: a case report. Int J Oral Maxillofac Implants 1997; 12: 558-61.

43. Mason ME, Triplett RG, Alfonso WF. Life-threatening hemorrhage from placement of a dental implant. J Oral Maxillofac Surg 1990; 48: 201-4.

44. Laboda G. Life-threatening hemorrhage after placement of an endosseous implant: report of case. J Am Dent Assoc 1990; 121: 599-600.

45. ten Bruggenkate CM, Krekeler G, Kraaijenhagen HA, Foitzik C, Oosterbeek HS. Hemorrhage of the floor of the mouth resulting from lingual perforation during implant placement: a clinical report. Int J Oral Maxillofac Implants 1993; 8: 329-34.

46. Mardinger O, Manor Y, Mijiritsky E, Hirshberg A. Lingual perimandibular vessels associated with life-threatening bleeding: an anatomic study. Int J Oral Maxillofac Implants 2007; 22: 127-31.

47. Dubois L, de Lange J, Baas E, Van Ingen J. Excessive bleeding in the floor of the mouth after endosseus implant placement: a report of two cases. Int J Oral Maxillofac Surg 2010; 39: 412-5.

48. Del Castillo-Pardo de Vera JL, Lopez-Arcas Calleja JM, Burgueno-Garcia M. Hematoma of the floor of the mouth and airway obstruction during mandibular dental implant placement: a case report. Oral Maxillofac Surg 2008; 12: 223-6.

49. Boyes-Varley JG, Lownie JF. Haematoma of the floor of the mouth following implant placement. SADJ 2002; 57: 64-5.

50. Jalili MR, Emaeelinejad M, Bayat M, Aghdasi MM. Appearance of anatomical structures of mandible on panoramic radiographs in Iranian population. Acta Odontol Scand 2011.

51. de Beer FC. Characteristics of the neutron/X-ray tomography system at the SANRAD facility in South Africa Nuclear Instruments and Methods in Physics Research Section A: Accelerators, Spectrometers, Detectors and Associated Equipment 2005; 542: 1-8. 